\title{
A Stability Study of Alkali Doped PBI Membranes for Alkaline Electrolyzer Cells
}

\author{
Jensen, Jens Oluf; Aili, David; Hansen, Martin Kalmar; Li, Qingfeng; Bjerrum, Niels Janniksen; \\ Christensen, Erik
}

\author{
Published in: \\ ECS Transactions
}

Link to article, DOI:

$10.1149 / 06403.1175$ ecst

Publication date:

2014

Document Version

Publisher's PDF, also known as Version of record

Link back to DTU Orbit

Citation (APA):

Jensen, J. O., Aili, D., Hansen, M. K., Li, Q., Bjerrum, N. J., \& Christensen, E. (2014). A Stability Study of Alkali Doped PBI Membranes for Alkaline Electrolyzer Cells. ECS Transactions, 64(3), 1175-1184.

https://doi.org/10.1149/06403.1175ecst

\section{General rights}

Copyright and moral rights for the publications made accessible in the public portal are retained by the authors and/or other copyright owners and it is a condition of accessing publications that users recognise and abide by the legal requirements associated with these rights.

- Users may download and print one copy of any publication from the public portal for the purpose of private study or research.

- You may not further distribute the material or use it for any profit-making activity or commercial gain

- You may freely distribute the URL identifying the publication in the public portal 


\title{
A Stability Study of Alkali Doped PBI Membranes for Alkaline Electrolyzer Cells
}

\author{
Jens Oluf Jensen ${ }^{\mathrm{a}}$, David Ailia, Martin K. Hansen ${ }^{\mathrm{b}}$, Qingfeng $\mathrm{Li}^{\mathrm{a}}$, Niels J. Bjerrum ${ }^{\mathrm{a}}$ and \\ Erik Christensen $^{\mathrm{a}}$ \\ ${ }^{a}$ Department of Energy Conversion and Storage, Technical University of Denmark, \\ Kemitorvet 207, 2800, Kgs. Lyngby, Denmark \\ b Siemens Corporate Technology, Borupvang 3, DK-2750 Ballerup, Denmark
}

\begin{abstract}
Polybenzimidazole membranes in a linear, a crosslinked and a thermally cured form were subjected to aging in $6 \mathrm{M}$ aqueous $\mathrm{KOH}$ at $85{ }^{\circ} \mathrm{C}$ for periods of up to 176 days. The aged membranes were characterized with respect to weight loss, mechanical properties and ionic conductivity. The area specific conductivity was similar to a commercial Zirfon membrane and suitable for a water electrolyzer. Some chemical degradation was seen during the aging period, but the crosslinked and the cured materials were both integral after 176 days of aging. A simplified electrolyzer test cell was operated successfully.
\end{abstract}

\section{Introduction}

Alkaline fuel cells and electrolyzers are attracting increasing interest. This is to a large extent due to the broad selection of catalyst materials not based on resource limited and expensive noble metals. The first fuel cells in practical use were Francis Thomas Bacon's based on an alkaline electrolyte. The system has been quite successful with good oxygen kinetics, but the electrolyte suffers from carbonization when operated in normal $\mathrm{CO}_{2}$ containing air and this has limited the application to space technology and similar niches. The alkaline electrolyzer on the other hand has been the state of art commercial choice for decades and the carbonization problem is absent since oxygen is produced, not consumed. However, the demand for high voltage efficiency has been limited and the alkaline electrolyzer has been optimized in the direction of robustness and long lifetime instead. Today it has become obvious that an energy system based on renewable energy will need conversion of a large amount of electrical energy to fuel for storage and for transport. We believe that from a materials perspective the alkaline electrolyzer has the strongest potential for meeting the manufacturing cost targets given, but voltage efficiency and rate capability must be improved significantly.

One important component with room for improvement is the electrolyte which traditionally fills a gap of up to several mm between the electrodes. The resistance can be much reduced if a thin anion conducting membrane or a porous diaphragm is used instead in direct contact with both electrodes (zero gap). There are at least three ways to provide anionic conductivity to a polymer membrane material. a) A porous membrane with the pores filled with aqueous base (preferably $\mathrm{KOH}$ ). This resembles the fibrous separator materials made of asbestos used in traditional electrolyzers. The main requirements are chemical stability and a high wettability towards the electrolyte. A drawback of such a system is that the membrane must have a significant thickness to secure gas separation 
and this causes increased ohmic resistance. b) An anion exchange membrane with cationic side chains (equivalent to the proton conducting perfluorosulfonic acids, e.g. Nafion, with anionic side chains). The side chains form hydrophilic channels with a high ionic strength which is the basis for the ionic conductivity. In proton exchange membrane (PEM) electrolyzers proton conducting membranes like in PEM fuel cells have been very successful, but for the equivalent anion exchange membranes a similar conductivity has not yet been demonstrated; in contrast it is typically about an order of magnitude lower, which is insufficient. See the review by Merle et al. (1). An advantage of the ion exchange membrane system is that one need not ad $\mathrm{KOH}$ (or acid) to the system since the mobile ions are contained and fixed in the membrane. c) a third possibility is to apply a membrane material in which aqueous $\mathrm{KOH}$ can be dissolved. Such a system can be understood as an intermediate between the two first. The $\mathrm{KOH}$ provides the conductivity like in the porous membrane, but since there are no real pores the risk of gas crossover is smaller and a thinner membrane can be applied. The membrane is thus tight against convection and that feature is has in common with then ion exchange membrane. Moreover it may have acidic sites that will ease the solubility of $\mathrm{KOH}$, but these functional groups are not placed in a way to form hydrophilic domains for sufficient ionic conductivity and consequently, free aqueous $\mathrm{KOH}$ must be added to the system. The three types of materials are sketched in Figure 1.

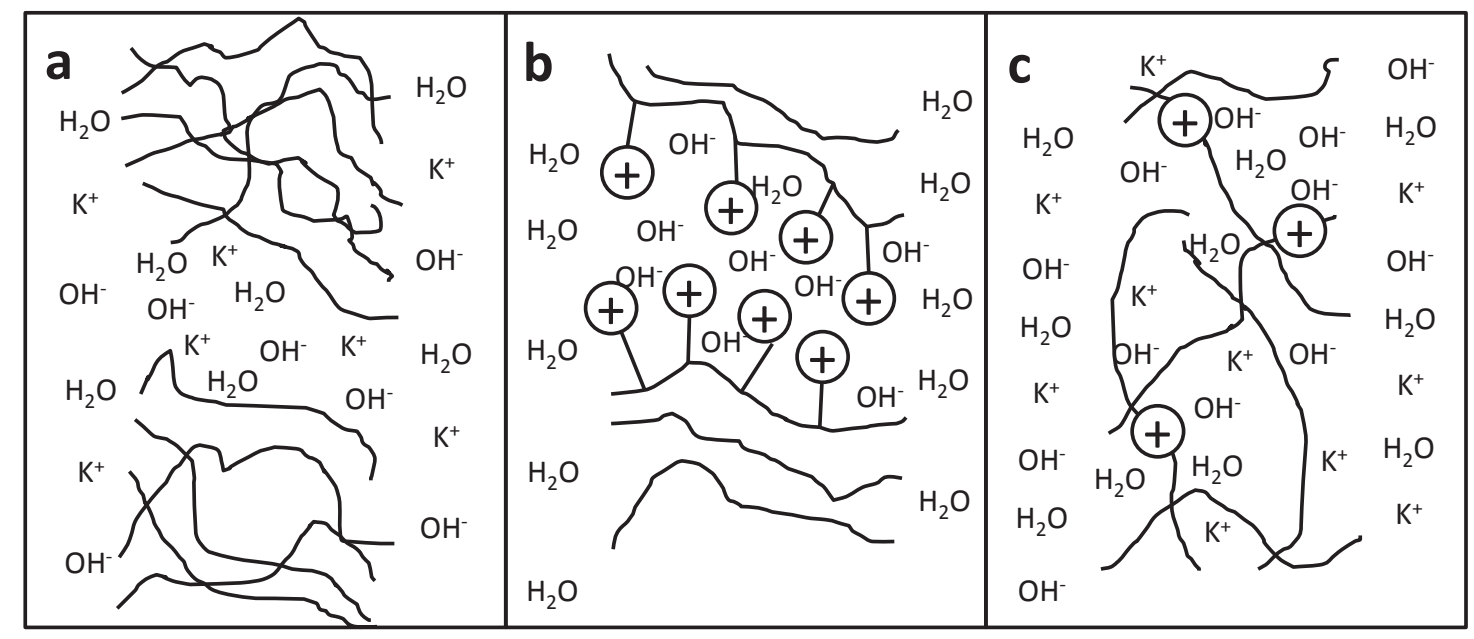

Figure 1. Three types of polymer based anion conducting membranes. a) A porous electrolyte filled membrane. b) An anion exchange membrane. c) A membrane with dissolved electrolyte.

\section{Objectives of the Study}

The aromatic fluorine free polymer polybenzimidazole (poly(2,2' $(m$-phenylene)5,5'bibenzimidazole), PBI) has been very successful as a high temperature PEM fuel cell membrane when doped with phosphoric acid (2) and it has been shown by Xing and Savadogo (3) that it can also be doped with potassium hydroxide and serve as electrolyte for alkaline fuel cells (type c in Figure 1). The polymer attains a cationic or an anionic form depending on the $\mathrm{pH}$ value after doping with an acid or a base. See figure 2. $\mathrm{p} K_{\mathrm{a}}$ is the acid constant of the neutral PBI and $\mathrm{p} K_{\mathrm{aH}}$ is the acid constant of the protonated form. $\mathrm{p} K_{\mathrm{a}}$ is most relevant here and it is reported to be 12.8 for benzimidazole (4). 
The present objective is to study the stability and suitability of PBI as an alkaline electrolyzer membrane when doped with aqueous $\mathrm{KOH}$.

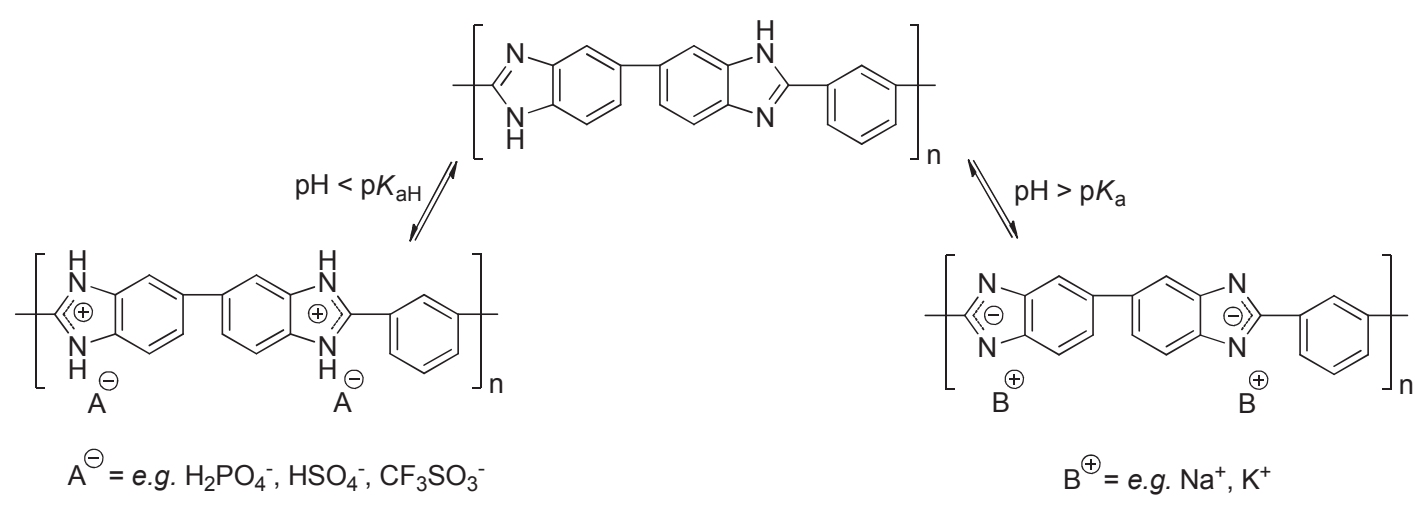

Figure 2. The two different ionomeric forms of PBI depending on $\mathrm{pH} . \mathrm{p} K_{\mathrm{a}}$ is the acid constant of the neutral PBI and $\mathrm{p} K_{\mathrm{aH}}$ is the acid constant of the protonated form.

\section{Experimental}

PBI ( $m$-PBI, Danish Power Systems) was solution cast from $N, N$-dimethylacetamide (DMAc, Aldrich). Crosslinking and thermal curing (at $350^{\circ} \mathrm{C}$ ) were carried out as described previously by Aili et al. (5) and $\mathrm{Li}$ et al. (6) respectively. Membrane pieces were weighed after drying in vacuum (dry weight) and then boiled in demineralized water for 2 hours and weighed again (soaked weight). The pieces were stored and aged in 6 molar aqueous $\mathrm{KOH}$ in closed PTFE bottles at $85^{\circ} \mathrm{C}$ for different periods of time up to 176 days after which the membranes were characterized.

Electrolyzer tests were made with electrodes of polished nickel plates (anode and cathode, both $22 \mathrm{~cm}^{2}$ ). Since the electrodes were massive they were placed about one mm away from the membrane on each side to allow for the gas evolution. The cell housing was made entirely of PTFE.

For additional experimental details refer to Aili et al. (7) where some of the present results are published.

\section{Results and Discussion}

\section{$\underline{\mathrm{KOH} \text { uptake and conductivity }}$}

The uptake of $\mathrm{KOH}$ and water in linear PBI is shown in Table I. KOH in excess of what it takes to neutralize the acidic sites of PBI is absorbed when the doping solution concentration is higher than $10 \mathrm{wt} . \%$. High $\mathrm{KOH}$ uptake is accompanied by high water uptake, but with a doping solution as high as $50 \mathrm{wt} . \%$ the water uptake has declined. This can be explained by the effect of reduced water activity as the $\mathrm{KOH}$ concentration increases. $25 \mathrm{wt} . \% \mathrm{KOH}$ in an aqueous solution (almost $6 \mathrm{M}$ ) is close to the 
concentration where the ionic conductivity peaks at room temperature. This is apparently reflected in the membrane conductivity as seen in Figure 3 where the conductivity is plotted as a function of the doping solution concentration. In an electrolyzer cell based on this membrane system the anolyte and catholyte will determine the concentration of $\mathrm{KOH}$ and water in the membrane and thus a concentration around 6 molar or 25-30 wt \% will be a good choice like in traditional electrolyzers.

TABLE I. $\mathrm{KOH}$ and water uptake in linear PBI as a function of $\mathrm{KOH}$ concentration $[\mathrm{KOH}]$ of the doping solution. $\mathrm{KOH}$ and water contents are expresses relative to the number of repeating units of PBI.

\begin{tabular}{ccc}
\hline$[\mathbf{K O H}](\mathbf{w t .} \%)$ & Excess $\mathbf{K O H} / \mathbf{P B I}_{\mathbf{R U}}$ & $\mathbf{H}_{\mathbf{2}} \mathbf{O} / \mathbf{P B \mathbf { I } _ { \mathbf { R U } }}$ \\
\hline 0 & 0 & 3 \\
5 & 0 & 5 \\
10 & 0 & 8 \\
20 & 0.3 & 14 \\
25 & 1.2 & 14 \\
50 & 1.7 & 6 \\
\hline
\end{tabular}

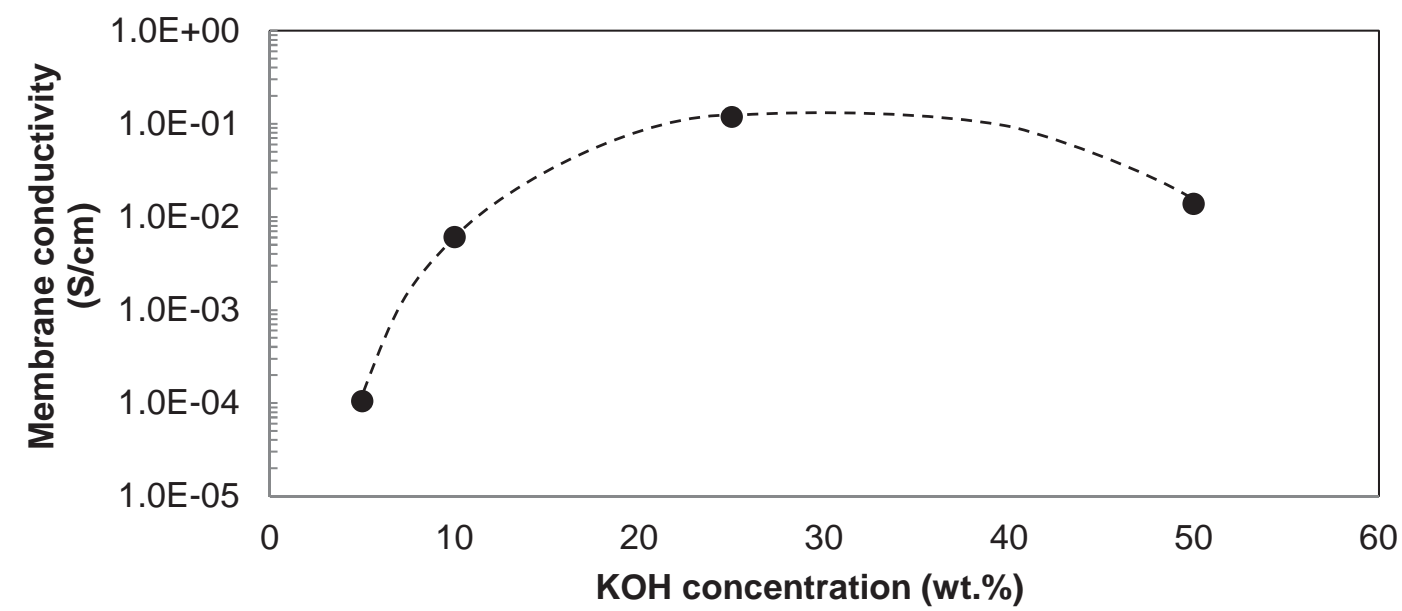

Figure 3. The conductivity of a doped linear PBI membrane as a function of the $\mathrm{KOH}$ concentration in the doping solution.

\section{Electrolyzer testing}

Electrolyzer single cells were tested at $80{ }^{\circ} \mathrm{C}$ in $30 \mathrm{wt} \% \mathrm{KOH}$. A commercial porous Zirfon membrane was also used for comparison. See Figure 4. All cells show high activation polarization (nonlinear voltage increase at current densities primarily below $100 \mathrm{~mA} \mathrm{~cm}^{-2}$ ). This was expected due to the flat nickel electrodes with very low surface areas. The more interesting parts of the curves are the almost linear part at higher current densities, for which the slope reflects the ohmic resistance of the cell, i.e. to a large extent the membrane resistance. The slopes are all comparable to that of the Zirfon membrane and this indicates that the PBI membranes can replace Zirfon in terms of area specific resistance. Zirfon filled with $\mathrm{KOH}$ has a lower specific resistance than $\mathrm{KOH}$ filled PBI, 
but electrolyzer membranes from Zirfon are significantly thicker and therefore they end up as more or less equal.

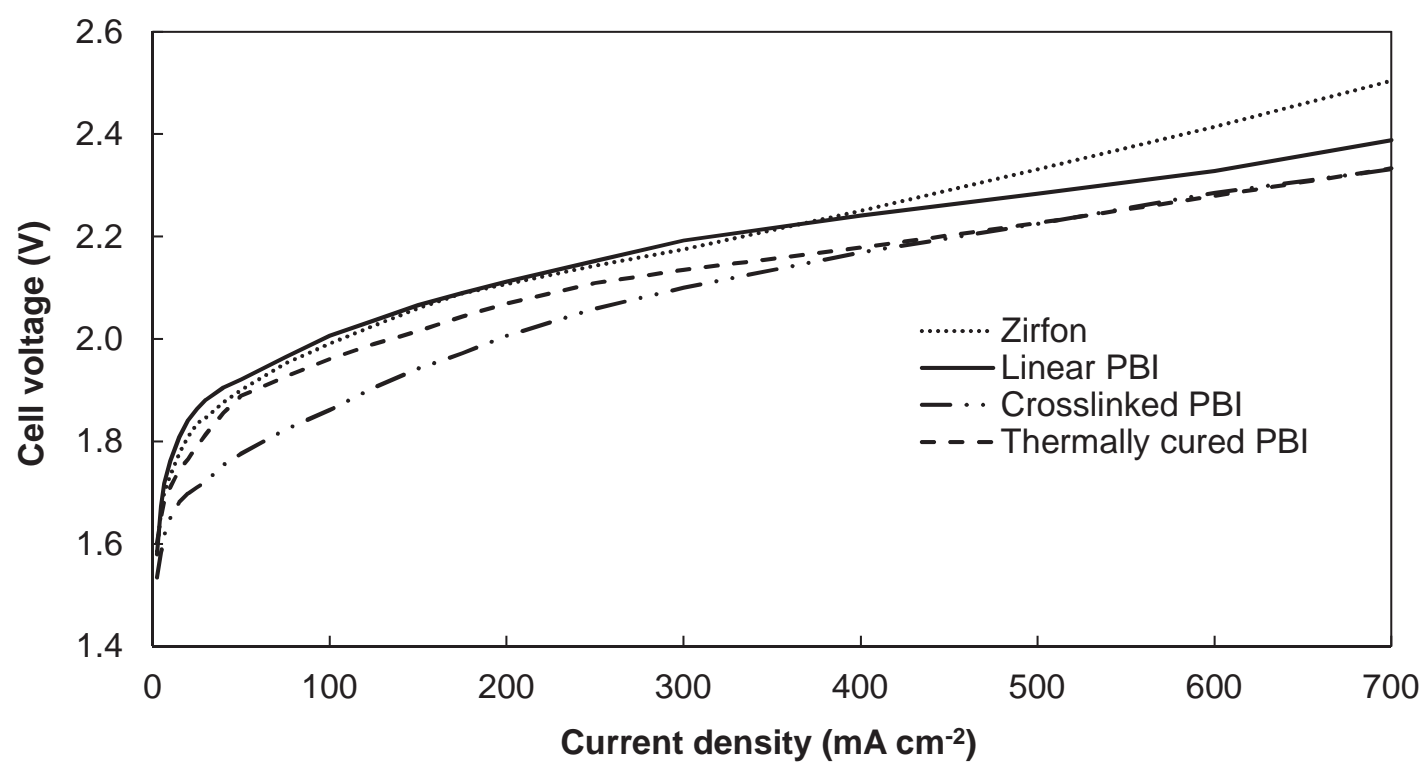

Figure 4. Polarization curves of the tested electrolyzer single cells carried out at $80{ }^{\circ} \mathrm{C}$ in 30 wt.\% KOH.

\section{$\underline{\text { Stability during storage in } \mathrm{KOH}}$}

The membrane pieces were all equilibrated in water before they were immersed and stored in $\mathrm{KOH}$. This accounts for the initial water content as seen in Figure 5. After immersion the uptake increases strongly and the weight fraction of PBI decreases from $83 \%$ to about $44 \%$. Already after 6 days (first characterization point) the membrane composition is very constant. The uptake behavior of the crosslinked and the cured PBI were almost identical and are not shown here. Samples of polysulfone (PSU), polyphenylene sulfide (PPS) and polytetrafluorethylene (PTFE) were also stored in KOH for comparison. As expected, these three polymers did not take up any significant amount of either water or $\mathrm{KOH}$.

The mechanical properties (Figure 6) exhibit the common trend that the three PBI based membranes are softened significantly when immersed in and thus doped with $\mathrm{KOH}$. This is accordance with the significant uptake of $\mathrm{KOH}$ and additional water. After this saturation the decrease of modulus and strength is much more moderate over the whole 176 day period. An exception is the linear PBI which disintegrated between the 116 and 176 day measurements. 


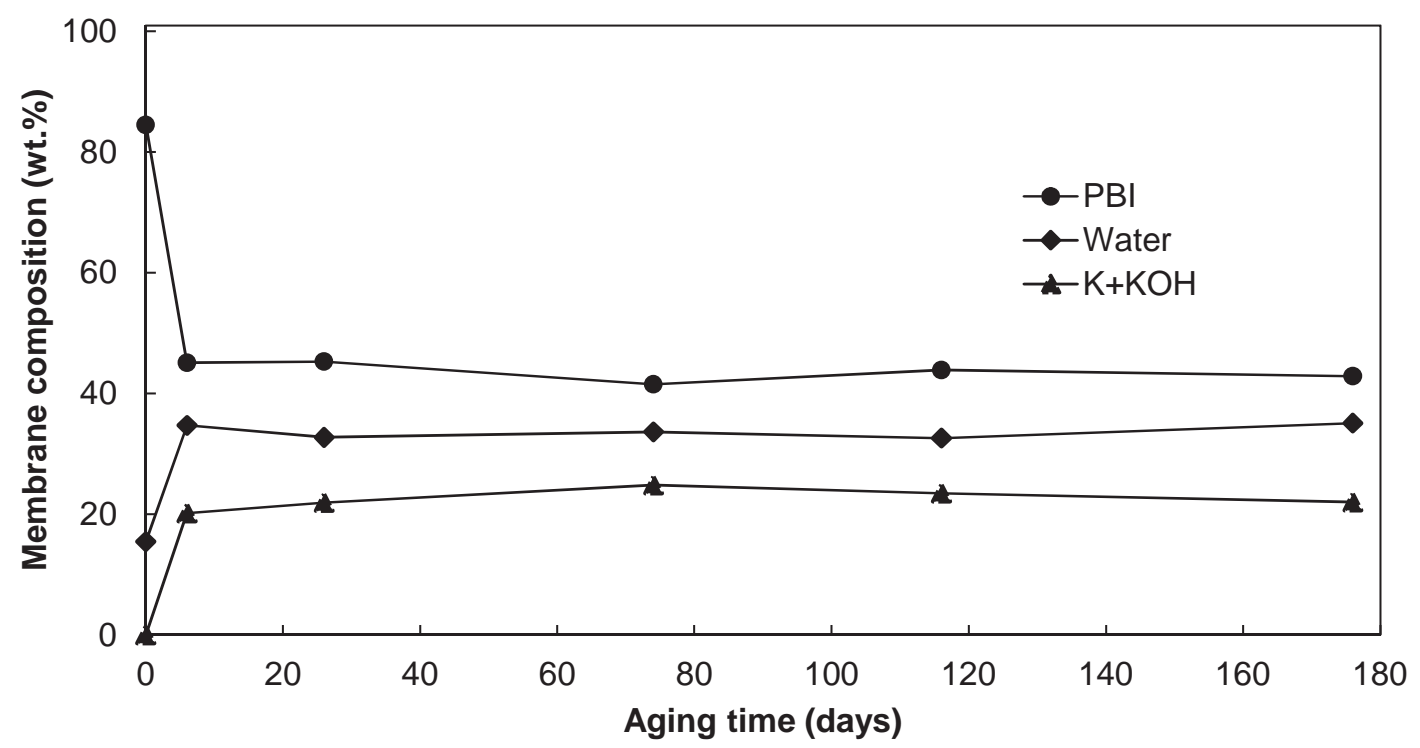

Figure 5. Composition of linear PBI after storage in $6 \mathrm{M} \mathrm{KOH}$ for up to 176 days.
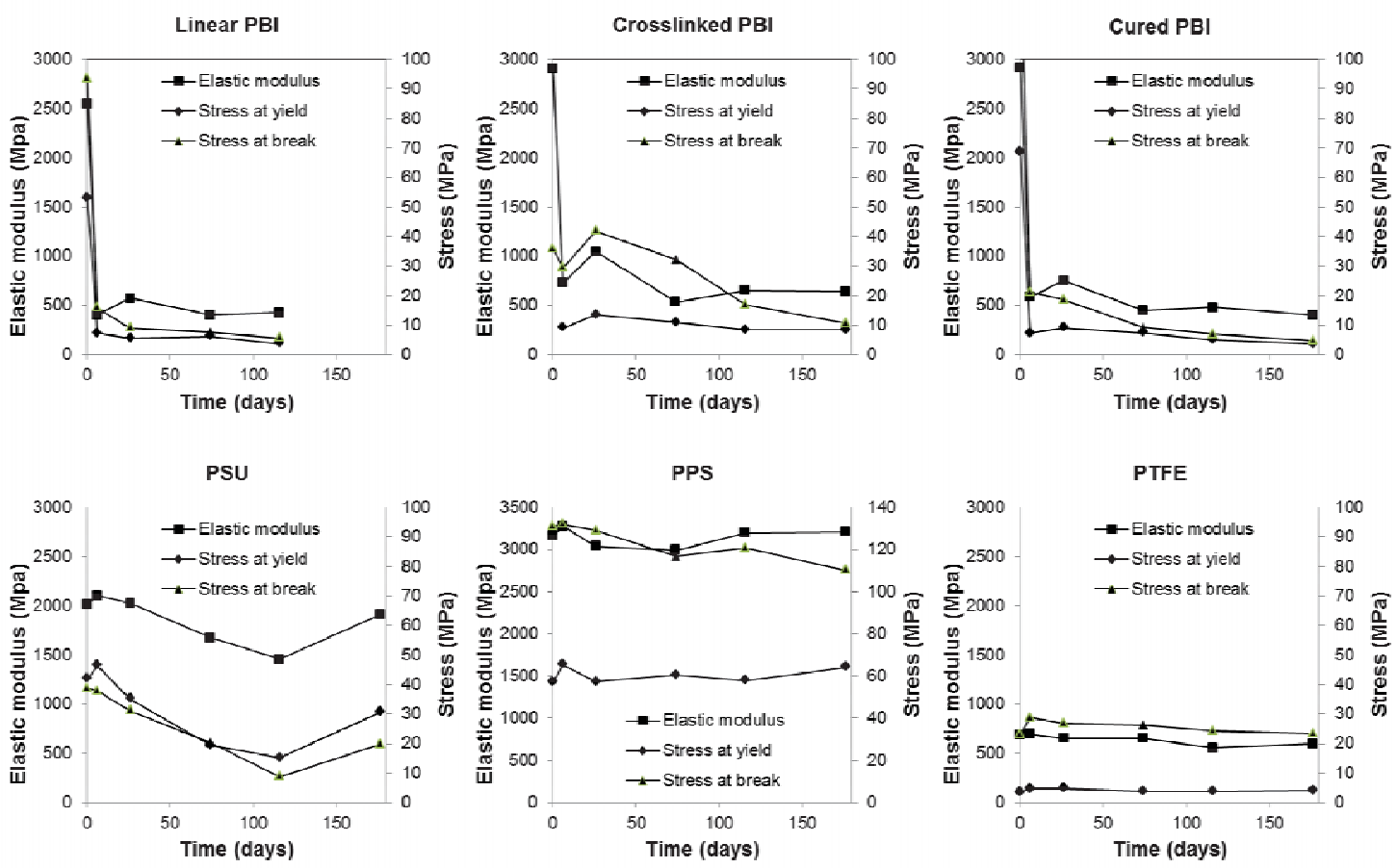

Figure 6. Mechanical properties the three kinds of PBI as well as PSU, PPS and PTFE. Note that the scale on the vertical axes for PPS are different from those of the others.

The apparent degradation was further studied by determination of the remaining mass (Figure 7) and the inherent viscosity (Figure 8) of the membranes and their polymers when possible. The mass was measured after washing out the $\mathrm{KOH}$ and using the soaked weight as reference. It is evident that crosslinked and especially thermally cured PBI 
keeps the mass better than linear PBI. Inherent viscosity is a common quantity for the assessment of the molecular weight of polymers. A decrease of inherent viscosity is a clear indication of reduced average molecular weight of the polymer of a membrane. The measurement was only possible for linear PBI, since the other types could not be dissolved in sulfuric acid.

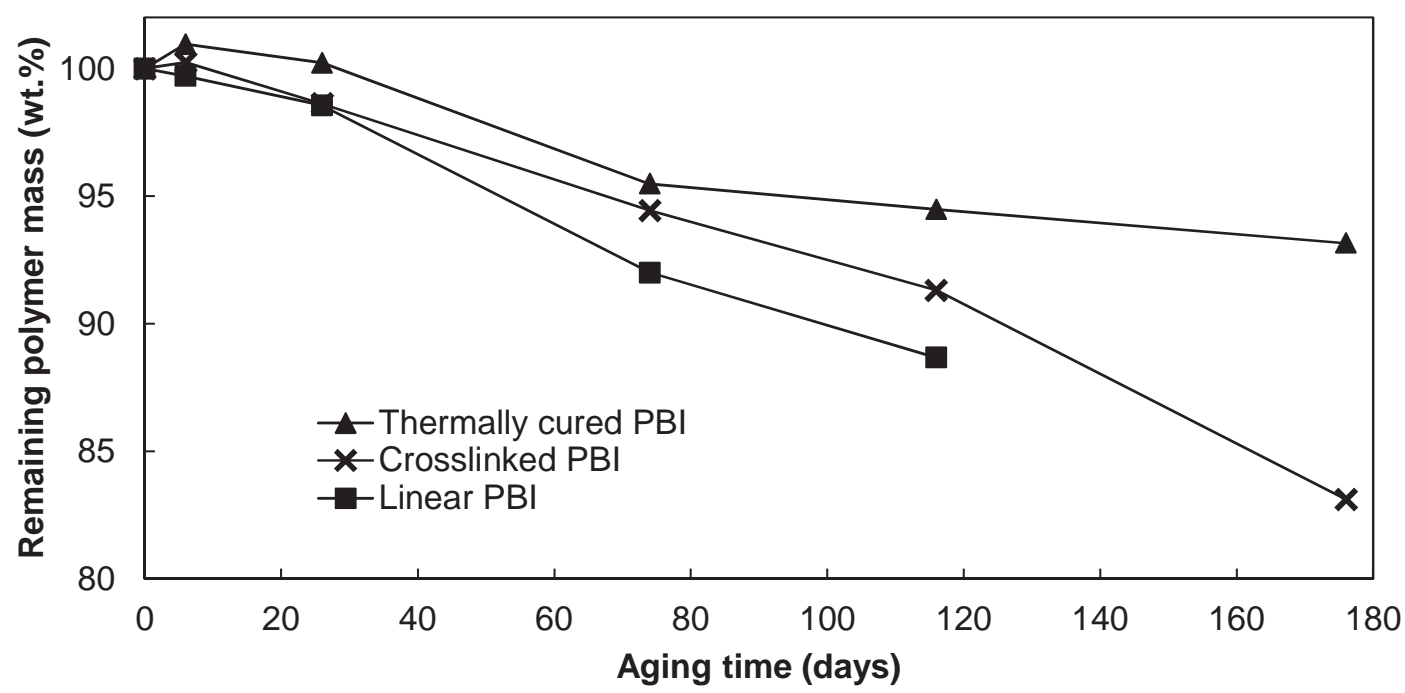

Figure 7. The remaining mass of the polymers after different aging times. The last point of linear PBI could not be measured because the membrane was disintegrated.

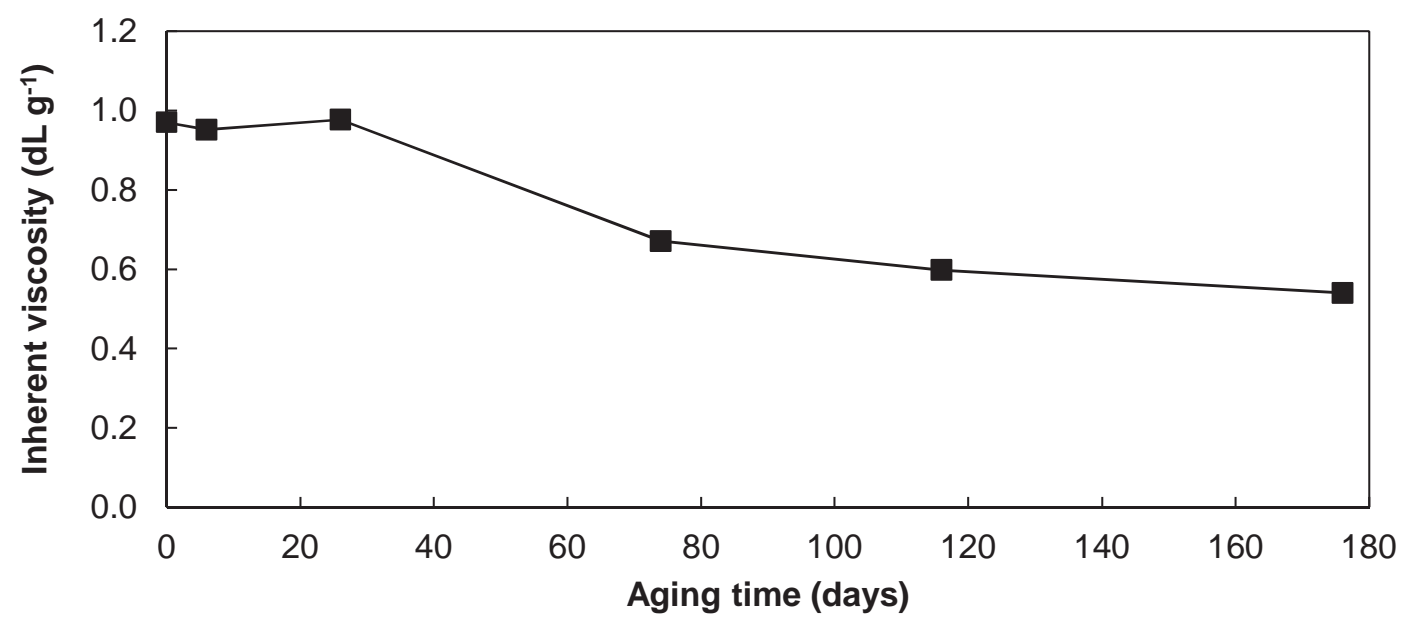

Figure 8. Inherent viscosity of linear PBI after storage in $6 \mathrm{M} \mathrm{KOH}$ at $85^{\circ} \mathrm{C}$. 


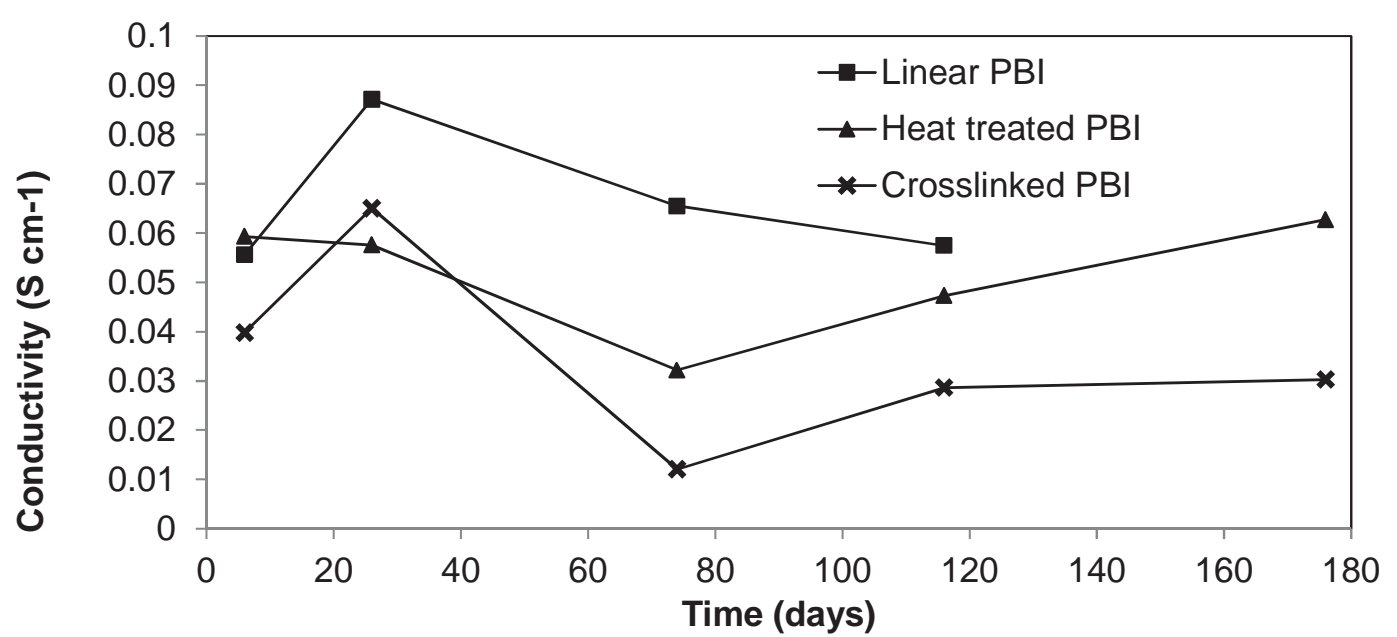

Figure 9. Room temperature through-plane conductivity of the three different kinds of $\mathrm{PBI}$ after storage in $6 \mathrm{M} \mathrm{KOH}$ for up to 176 days.

The measured room temperature conductivity is plotted as a function of storage time in $6 \mathrm{M} \mathrm{KOH}$ in Figure 9. The values are scattered and it is difficult to justify a trend in the development or in the relation between the different kinds of PBI. The scattering is most likely related to the way of measurement since the constant content of $\mathrm{KOH}$ and water seen in Figure 5 would lead to the anticipation of a constant conductivity.

\section{$\underline{\text { Discussion }}$}

The area specific conductivity of the $\mathrm{KOH}$ doped $\mathrm{PBI}$ membranes are comparable to that of the commercial Zirfon and the materials are thus viable for commercial electrolyzer in that aspect, although a higher conductivity is desirable for high load applications. It was also seen that the test electrolyzers behaved similarly. The high voltage was to a large extent due to the poor electrodes which were used for simplicity.

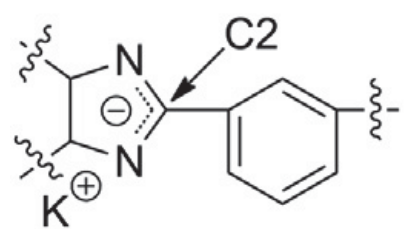<smiles>CC(C)O</smiles>

Figure 10. Proposed point of attack for alkaline hydrolysis.

The main issue is the chemical stability. The cured or crosslinked membranes lasted the full 176 day test period, but with some degradation. The moderate weight loss in combination with the more severe loss of inherent viscosity suggests chain scission as the dominating degradation mechanism. This is also supported by a spectroscopic characterization which is not reproduced here. See (7). The weak point of PBI is believed to be as indicated on figure 10. An opening of the polymer in this position is actually the reverse of the polymerization process. One might wonder why the crosslinked and cured 
membranes showed a slower degradation despite they contain the same vulnerable positions. It is possible that the same bond breaking takes place but that the links keep the material integral for a longer time. Another possibility is that the links impose electronic or steric effects on the polymer slowing down the bond breaking. The thermal treatment (curing) may also lead to some crosslinking or at least a stronger association of the polymer chains since the polymer becomes insoluble.

An aging period of almost half a year in $6 \mathrm{M} \mathrm{KOH}$ at $85^{\circ} \mathrm{C}$ is long and would severely affect most materials. In the case of the three variants of PBI studied the decay is although limited still significant and too high for commercial electrolyzers which are expected to work for several years. It is clear that crosslinking or thermal curing improves the stability of $\mathrm{PBI}$ in $\mathrm{KOH}$. Other recent studies suggest modifications of PBI to increase the stability. Henkensmeier et al. (8) addresses electronic effects while Thomas et al. (9) uses steric hindrance.

\section{Conclusion}

The area specific conductivity of the PBI membranes is high enough to be of interest for commercial electrolyzers. At least it is comparable to that of commercial porous membranes like Zirfon.

The main issue is chemical stability. In aqueous $\mathrm{KOH}$ at $85^{\circ} \mathrm{C}$ the materials are not yet satisfactory since a clear decay is seen after only half a year. The degradation mechanism suggested is polymer hydrolysis which might be limited further by modification of the polymer.

\section{Acknowledgments}

The authors wish to acknowledge financial support of the presented work by the Danish Council for Independent Research, Technology and Production Science (Grant no. 11-117035/FTP). Moreover, Danish Power Systems is acknowledged for supplying PBI.

\section{References}

1. G. Merle, M. Wessling and K. Nijmeijer. J. Membrane Sci. 377, 1 (2011).

2. Q. Li,J.O.Jensen,R.F.Savinell and N.J.Bjerrum. Progr. Polym. Sci.34, 449 (2009).

3. B. Xing and O.Savadogo. Electrochem. Commun. 2, 697 (2000).

4. H. Walba and R.W. Isensee. J. Org. Chem. 26, 2789 (1961).

5. Q. Li, C. Pan, J. O. Jensen, P. Noyé and N. J. Bjerrum. Chem.Mater. 19, 350 (2007).

6. D. Aili, L. N. Cleemann, Q. Li, J. O.Jensen, E. Christensen and N.J.Bjerrum. J. Mater. Chem. 22, 5444 (2012).

7. D. Aili, M. K. Hansen, R. F. Renzaho, Q. Li, E. Christensen, J. O. Jensen and N. J. Bjerrum. J. Membr. Sci. 447, 424 (2013). 
8. D. Henkensmeier, H. Cho, M. Brela, A. Michalak, A. Dyck, W. Germer, N. M. H. Duong, J. H. Jang, H.-J. Kim, N.-S. Woo and T.-H. Lim. Int. J. Hydrogen Energy 39, 2842 (2014).

9. O. D. Thomas, K. J. W. Y. Soo, T. J. Peckham, M. P. Kulkarni, and S. Holdcroft. J. Am. Chem. Soc. 134, 10753 (2012) 